\title{
Assessment of the impact of breast cancer on women in Gombe State, Northeastern Nigeria
}

\author{
Jonah H. Japhet ${ }^{1}$, Dathini Hamina*2, Doka J. S. Pauline ${ }^{3}$, Kever R. Teryila ${ }^{2}$, Habu Haruna ${ }^{2}$, Uba M. Njida ${ }^{2}$, Emma \\ Yagana ${ }^{4}$, Langa Mshelia ${ }^{1}$ \\ ${ }^{1}$ Nursing Department, Ministry of Health Gombe, Gombe, Nigeria \\ ${ }^{2}$ Department of Nursing Science, University of Maiduguri, Maiduguri, Nigeria \\ ${ }^{3}$ Administration, College of Nursing and Midwifery Gombe, Gombe, Nigeria \\ ${ }^{4}$ Nursing Department, Hospital Management Board Borno State, Borno, Nigeria
}

Received: May 7, 2018

DOI: $10.5430 /$ jst.v9n1p33
Accepted: September 12, $2018 \quad$ Online Published: January 29, 2019

URL: https://doi.org/10.5430/jst.v9n1p33

\begin{abstract}
Objective: The aim of the study is to assess the physical, financial, emotional and social impact of breast cancer on women in North east Nigeria.

Methods: A qualitative transcendental phenomenological study design was adopted, using face-to face unstructured interview to collect data from 22 respondents who were recruited via purposive non-probability sampling technique. The interviews were recorded, transcribed verbatim and further analyzed using thematic analysis method into themes and sub-themes.

Results: The result revealed excruciating pains that does not abate completely as the main physical impact, expensive cost of treatment as the major financial impact and crying as the major emotional impact of breast cancer on women. However, been diagnosed with breast cancer had no any consequences on participants' relationship with spouse or family members.

Conclusion: Breast cancer causes pain, makes women to cry and the treatment is very expensive but it does not cause relationship problems. There is therefore the need for Government and Non-governmental policies to be geared towards supporting women with breast cancer to overcome these challenges.
\end{abstract}

Key Words: Breast cancer, Physical impact, Financial impact, Emotional impact, Social impact, Nigeria

\section{INTRODUCTION}

Evidence described cancer as a twenty first (21st) century global health problem. ${ }^{[1]}$ Among the different types of cancer, breast cancer is the second most common type and also the most common cancer among women worldwide with about 1.7 million new cases diagnosed every year. ${ }^{[2]}$ Again, breast cancer is known to be the most common cause of cancer mortality among women in developing countries and the second most common cause of mortality with lung cancer being first among women in developed countries. ${ }^{[3]}$

Many studies have revealed that women's knowledge about early diagnosis and screening of breast cancer can change their screening seeking behavior. ${ }^{[4]}$ Therefore, breast cancer is frequently diagnosed among older women than in younger ones because younger women tend to have more knowledge on the disease. ${ }^{[5]}$ More so, the incidence rate increases sharply with age, which is about $9 \%$ at youth age but slows down to $3 \%$ after menopause. ${ }^{[6]}$ Evidence further

\footnotetext{
* Correspondence: Dathini Hamina; Email: haminadathini@yahoo.com; Address: Department of Nursing Science, University of Maiduguri, Maiduguri, Nigeria.
} 
indicates that since $1950 \mathrm{~s}$, breast cancer incidence rate has been increasing globally but the incidence has doubled in lower risk countries (developing countries). Conversely, the survival rate varies; from $80 \%$ in Europe (high income countries) to $60 \%$ in middle income countries and $40 \%$ in low income countries. ${ }^{[7]}$ Furthermore, in Africa breast cancer is reported to be 1 in 4 diagnosed cancers and 1 in 5 cancer deaths in women, thus making it the most lethal type of cancer among women. ${ }^{[8]}$ In the same light, the incidence continue to increase which is projected to double by the year 2050 with majority of the patients presenting with advanced stage breast cancer.

On the impact of breast cancer, it is widely known that breast cancer does not come and go without impact or negative effect on its victims as it affects every aspect of victim's life. ${ }^{[9]}$ In the same light, it was also revealed that breast cancer has a profound impact on women's health right from diagnosis ${ }^{[10]}$ and this impact can persist for at least 10 years even after treatment. ${ }^{[11]}$ In addition, the united states Food and drug administration (FDA), held a public meeting to hear perspectives from people living with breast cancer and the interview revealed that breast cancer has a negative impact on all aspects of victims' health (physical, financial, emotional and socially). Physical impact includes fatigue, weakness, pain, gastro-intestinal problems, anemia, peripheral neuropathy, weight fluctuation, lymphedema, inability to perform activities of daily living, and sexual problems such as loss of libido and pain during sexual intercourse. Psychological impact include depression, anxiety, fear, emotional burden, worry about future, cognitive problems and chemo-brain. Social impact include stigma, social isolation, stress on intimate relationship and bad relationship with people while financial problems include cost of treatment, reduced working time because of illness, and loss of job. ${ }^{[12]}$

Many researches were conducted on breast cancer prevention awareness in Nigeria ${ }^{[13-15]}$ but to the authors knowledge there is no single study on the impact of breast cancer on women in northern Nigeria. This study therefore aims to study the physical, financial, psychological and social impacts of breast cancer on women in Northern Nigeria in order to add more knowledge to the existing literature which could be used as a reference tool for body of academia. More so, the study will reveal to the general public what breast cancer patients are passing through physically, financially, socially and psychologically as such it will guide them in associating with the patients. Finally, the main question of the study is: what are the physical, financial, psychological and social impacts of breast cancer among women in Northern Nigeria.

\section{MeTHODS}

\subsection{Research design}

Qualitative transcendental phenomenological study design was adopted for this study. This design is deemed felicitous because the study is concerned with subjective assessment of respondents' perspective based on their experience. More so, the transcendental phenomenology approach focuses on the respondents' given descriptions to generate essence of their various experiences.

\subsection{Area of study}

This research work was conducted in Gombe State located in the North eastern part of Nigeria. Furthenbjhurmore, Gombe state is considered multi-ethnic in nature, mainly consisting of Fulani, Tangale, Waja, Tera, Pero, Tula, Bolawa, Cham, Lunguda, Dadiya, Kamo, and Awak, as the major tribes. More so, Hausa, Fufulde, Tangale, Tera and Waja is the most commonly spoken languages. ${ }^{[16]}$ According to 2006 census majority of the population of Gombe state are men (about 1.2 million) and women (1.1 million). Adults within the ages of $15-64$ years are 1.17 million. ${ }^{[17]}$

\subsection{Target population}

The target populations for this study were women aged 18-75 years from the 11 Local Governments of Gombe state who are diagnosed with breast cancer. Women within this age bracket were chosen because of the following:

- Females within this age range have a greater susceptibility to breast cancer

- They fall within the puberty stage when breast development starts, reproductive and menopausal stages when the disease is most likely to present

- They are the one that are most likely to feel the impact of breast cancer.

\subsection{Sample and sampling technique}

Purposive Non-probability sampling technique was adopted for the study. Furthermore, hospital records of patients were used to recruit twenty (22) breast cancer patients that were diagnosed by a group of professional medical doctors in Federal Teaching Hospital Gombe and State specialist hospital Gombe. 15 participants were recruited from Federal teaching hospital Gombe, while 7 were identified in State specialist hospital, the two major hospitals in the state.

\section{Inclusion criteria}

- Women at any stage of the disease. From stage 1 to stage 4.

- Women at all the stages of treatment. From diagnosis to mastectomy. 
- Women from all the socio-economic background in (high, middle and low income socio-economic backgrounds).

- Women diagnosed of breastcancer by team of medical doctors in federal teaching hospital gombe and state specialist hospital Gombe, Northeastern Nigeria, Gombe state.

\subsection{Instruments for data collection}

Two instruments were used to collect data from respondents. These are interview guide and patients' hospital records. The unstructured interview was configured in 5 sections and questions were asked in an open-ended form. The sections are: Respondents demographic data (section A), physical impact (section B), financial impact (section C), Psychological impact (section D) and social impact (section D). Notably, this method of data collection was used because concepts can be clarified; there is more opportunity for respondents to express ideas in their own way, say what is important to them and explore issues in depth. ${ }^{[18]}$ Patients' hospital records were used to gather information on breast cancer details. These methods were employed because patients could not give details pertaining breast cancer. Therefore, their hospital records was used to collect data on age of diagnosis, years diagnosed, type of breast cancer and stage of breast cancer at time of diagnosis.

\subsection{Validity and reliability of the instrument}

To ascertain the validity of the instrument, face validity was done and the instrument was later presented to jurors in the field of cancer for their valuable vetting and input for the relevance of the content, clarity of the statement and logical accuracy of the instrument. Corrections made were effected and used to modify the final instrument before data collection. To ensure a high reliability of the interview, one-to-one interviews were conducted. ${ }^{[19]}$ More so, the interview was conducted by one interviewer this also leads to high tendencies of replicating same result. In addition, inter-rater scale was used to test the reliability of the instrument, the meta-analysis of the result revealed a high coefficient of 0.5 .

\subsection{Ethical consideration}

Application letter for ethical clearance was written to the Chief Medical Director of Federal Teaching Hospital Gombe and Director of ethics and research ministry of health Gombe. The application was along with the research proposal which contained relevant information about the nature of study. Thereafter, ethical clearance was obtained from the Hospitals where the study was conducted. Similarly, informed consent was obtained from respondents and was assured of anonymity and confidentiality. More so, respondents' wishes and rights are respected throughout the period of data collection including the right to withdraw from the study at any time they wish. Furthermore, respondents were treated with respect, dignity and their rights and welfare were protected. Finally, honesty and truthfulness was imbibed as the researcher did not alter or manipulated any with any part of the results.

\subsection{Procedure for data collection}

Ethical clearance letter was shown to the chief nursing officer on duty who introduced the researcher to the respondents. Afterwards, respondents were given details pertaining the research and information on how the interview will be conducted. After signing of the consent form both by the participant and witness, the interview was conducted verbally by the researcher using one-to-one approach. The interview was conducted mainly in Hausa language which is the general language spoken in Northern Nigeria. ${ }^{[20]}$ However, those who could not speak Hausa, an interpreter was recruited who is fluent in Hausa and Fufulde. The interview was recorded using a tape recorder and each lasted for about 10-15 minutes. After the interview, the respondents were appreciated and thanked for cooperation. For the patients hospital record, a checklist was used which contains three (3) items: age of diagnosis, type of breast cancer, stage of breast cancer at time of diagnosis and years diagnosed.

\subsection{Method of data analysis}

The recorded interview was translated and transcribed in English language by the researcher. Thereafter, thematic content analysis was used to qualitatively analyze the transcribed data obtained from the interview. This method is suitable to analyze the data obtained from interview because it aims at finding common patterns across a data set. The following steps were followed:

- Getting familiar with data by reading and re-reading

- Coding (labelling) of the whole text

- Searching for themes with broader patterns of meaning

- Reviewing themes to make sure they fit the data

- Defining and naming themes

- The write up: creating narratives that include quotes from the interviewees. ${ }^{[21]}$

\section{Results}

\subsection{Details of the respondents}

Initially, a total of twenty two (22) respondents were interviewed and the garnered data was analyzed based on the objectives of the study. Afterward, the qualitative data collated via interview were recorded by the researcher. More so, comments made by the women predominantly in Hausa and Fufulde language were further translated into English language and transcribed verbatim by the researcher. Accuracy 
of the translation was validated by a community member who is fluent in Hausa and Fufulde. Then, narratives were explored using qualitative method known as thematic analysis in order to identify, analyze, and explore themes within the generated data.

Table 1 reveals the specific details of the whole 22 respondents that participated in the study. All the respondents were given a pseudonym in order to honour the confidentiality agreement signed before the data was collected. Out of the
22 respondents, 17 are Muslim women while 5 are Christians. More so, all of the respondents are within the Northeastern part of Nigeria with 19 having Gombe as their state of domicile while the other 3 live in Bauchi, Borno and Adamawa state. More so, majority of the respondents are housewives, 4 are civil servants while 2 are traders of which majority never attended any form of formal education, 4 attended only primary school, 4 attended secondary school, while 2 attended tertiary institution having Islam as the chief religion and Christianity.

Table 1. Socio-demographic characteristics of respondents

\begin{tabular}{|c|c|c|c|c|c|c|c|}
\hline $\mathbf{S} / \mathbf{N}$ & $\begin{array}{l}\text { Respondents } \\
\text { pseudonyms }\end{array}$ & Age & Level of education & Occupation & Tribe & Religion & State of domicile \\
\hline 1. & Fauziya & 37 & Secondary & Civil servant & Fulani & Islam & Borno \\
\hline 2. & Mary & 72 & Never attended & House wife & Tula & Christianity & Gombe \\
\hline 3 & Sadiya & 62 & Never attended & housewife & Fulani & Islam & Gombe \\
\hline 4. & Farida & 80 & Never attended & housewife & Fulani & Islam & Gombe \\
\hline 5. & Hauwa & 77 & primary & housewife & Fulani & Islam & Gombe \\
\hline 6. & Maryam & 34 & Never attended & housewife & Fulani & Islam & Gombe \\
\hline 7 & Halima & 50 & Never attended & housewife & Fulani & Islam & Gombe \\
\hline 8 & Aisha & 55 & Never attended & housewife & Fulani & Islam & Adamawa \\
\hline 9 & Talatu & 18 & secondary & student & Fulani & Islam & Bauchi \\
\hline 10 & Fatima & 54 & Never attended & housewife & Fulani & Islam & Gombe \\
\hline 11 & Halira & 22 & secondary & housewife & Fulani & Islam & Gombe \\
\hline 12 & Suwaiba & 32 & Never attended & housewife & Fulani & Islam & Gombe \\
\hline 13 & Samira & 54 & Never attended & housewife & Wurkun & Islam & Gombe \\
\hline 14 & Blessing & 47 & tertiary & Civil servant & Tangale & Christianity & Gombe \\
\hline 15 & Falmata & 56 & Never attended & housewife & Tera & Islam & Gombe \\
\hline 16 & Ibome & 56 & primary & trader & Tangale & Christianity & Gombe \\
\hline 17 & zainab & 38 & Never attended & House wife & Tera & Islam & Gombe \\
\hline 18 & Hajara & 50 & primary & trader & Fulani & Islam & Gombe \\
\hline 19 & Khadija & 52 & Never attended & housewife & Fulani & Islam & Gombe \\
\hline 20 & Rabi & 63 & primary & housewife & Tera & Islam & Gombe \\
\hline 21 & Deborah & 53 & secondary & Civil servant & Tera & Christianity & Gombe \\
\hline 22 & konkebe & 49 & tertiary & Civil servant & Tangale & Christianity & Gombe \\
\hline
\end{tabular}

Table 2 shows the specific details of the age of diagnosis, stage at time of diagnosis and years diagnosed with breast cancer. This data was obtained from the patients' record. Diagnosis was done by a team of qualified medical doctors in federal teaching Hospital Gombe and State specialist hospital Gombe with majority of the respondents being diagnosed with advanced stage breast cancer. At the time of collecting the data, the respondents were on various treatments; some were on wound dressing, some receiving chemotherapy while some had already underwent mastectomy.

Additionally, the mean of their ages at time of diagnosis is 48 , while the standard deviation is 14.2 .

\subsection{Thematic analysis of qualitative data}

A total of t wenty two (22) individual face-to-face interviews were conducted by the researcher and each interview took about 10 to 15 minutes. More so, out of the 22 interviews, 16 were conducted in federal teaching hospital Gombe while 6 were done in State specialist hospital Gombe. Thematic analysis of the data revealed four (4) main themes with subthemes within each and are all related to the impact of breast cancer on its victims. These themes and their sub-themes are presented in Table 3. Furthermore, each theme is described in details below using bold upper cases while bold italics were used to represent sub-themes that emerged. More so, participants' quotations are also used to verify the identified themes. 
Table 2. Breast cancer detail of respondents

\begin{tabular}{lllll}
\hline S/N & $\begin{array}{l}\text { Respondents' } \\
\text { pseudonym }\end{array}$ & $\begin{array}{l}\text { Age of } \\
\text { diagnosis }\end{array}$ & $\begin{array}{l}\text { Stage at time } \\
\text { of interview }\end{array}$ & $\begin{array}{l}\text { Years } \\
\text { diagnosed }\end{array}$ \\
\hline 1. & Fauziya & 38 & Stage 4 & 1 \\
2. & Mary & 70 & Stage 4 & 2 \\
3 & Sadiya & 60 & Stage 4 & 2 \\
4. & Farida & 75 & Stage 4 & 5 \\
5. & Hauwa & 75 & Stage 4 & 2 \\
6. & Maryam & 30 & Stage 4 & 4 \\
7 & Halima & 48 & Stage 4 & 2 \\
8 & Aisha & 50 & Stage 4 & 5 \\
9 & Talatu & 15 & Stage 4 & 3 \\
10 & Fatima & 50 & Stage 4 & 4 \\
11 & Halira & 20 & Stage 4 & 2 \\
12 & Suwaiba & 31 & Stage 2 & 1 \\
13 & Samira & 49 & Stage 4 & 5 \\
14 & Blessing & 43 & Stage 4 & 4 \\
15 & Falmata & 54 & Stage 3 & 2 \\
16 & Ibome & 55 & Stage 2 & 1 \\
17 & zainab & 34 & Stage 4 & 4 \\
18 & Hajara & 45 & Stage 4 & 5 \\
19 & Khadija & 50 & Stage 4 & 2 \\
20 & Rabi & 61 & Stage 3 & 2 \\
21 & Deborah & 48 & Stage 4 & 5 \\
22 & konkebe & 46 & Stage 4 & 3 \\
\hline & & & & \\
\hline
\end{tabular}

\subsubsection{Body problems}

This theme highlights the physical impact of breast cancer on the women. All the women voiced out the various problems associated with breast cancer. The theme was further considered into the following sub-themes:

\section{Onset of physical problems}

All the women narrated different version of the initial onset of breast cancer. The different version of the stories include initial onset as a small swelling on the breast with or without fever that usually recede. One woman with right breast cancer diagnosed at stage 4 reported history of fever and small swelling that recedes with over the counter drug initially.

"The breast cancer started with fever and a small swelling in my breast, so I took a drug at home and it subsides." Fauziya.

Similarly, a respondent reported history of small swelling as a result of workout on a treadmill machine coupled with nosebleed and fever.

"It started when I climb an exercise machine. When I did it the second time, I couldn't continue, so blood started to pool in my chest and spread to my breast which eventually swells up. Then it leads to bleeding from my nose and a chronic fever that don't subside even after bathing" Sadiya.

Published by Sciedu Press
Another woman reported a history of small swelling only; "it has started as a small swelling on my breast" Aisha. In describing the onset of the disease, some of the respondents revealed that the swelling occurred intermittently but recedes with local home treatment to the point that it doesn't abate despite any type of traditional treatment or home remedy, which is the time they usually visit the hospital.

"The small swelling will subside but kept on coming back again to the point that could not be cured again" Halima.

\section{Pain}

Pain is the most recurrent sub-theme that emerged from the transcribed interview. The cancer pain is described as a chronic one that doesn't completely subside but subsides only for a little time and resurfaced later.

"My breast always pain me and I don't know how to describe the pain because it doesn't go away completely". Halira.

Another woman describe it as very painful: "when it start to pain me, it is very painful". Furthermore, one of the most educated women among them describe the pain like this:

"The description of this type of pain is like a piercing pain through my breast. In fact it is more than the pains of labour". Konkebe.

More so, the severity of the pain affects their sleeping pattern. Anytime it begins, women reported that it lead to the point they can't even sleep. Some have short sleeps that is not satisfactorily to them.

"This piercing pain gives me sleeping problems; I can't sleep when the pains start. Sometimes I can only sleep while sitting but can't do it while lying down”. Samira.

\section{Breast changes}

Breast cancer affects women's breast size and shape as it swells, had wounds on the breast to the point that some are surgically removed (mastectomy). This alter the women's body image (breast).

"The disease has chopped off my left breast" Mary.

In addition to reporting wound on the breast, some reported increase in breast size.

"My breast swelled up to a big size which is very painful”. Hauwa.

More so, another woman reported increase in breast size and metastasis that lead to mastectomy. 
"My breast swelled up, then it spreads to my arms and leg. When I came here, the doctors had to remove the right breast in the theatre. That is why am having only one breast now" Talatu.

\section{Vital signs changes}

Women reported perceived significant changes in their vital signs. The reported vital signs that had significant changes were respiration and temperature. Women expressed difficulties with respiration and also extreme persistent fever.

"When the fever starts, it doesn't subside even after bathing. At times after bathing the water on my body will evaporate and become like steam just because of the heat in my body". Aisha.

"I do feel chest pain and dizziness. Sometimes my breath will be ceasing". Suwaiba.

\section{Skin problems}

Majority of the respondents (18 out of 22) voiced out concerns about skin problems such as darkening of the skin and alopecia especially after chemotherapy. This skin problems are associated to the effects of chemotherapy.

"My skin becomes darker than normal and my hair fall off. Sometimes it comes with vomiting and I was informed by the health workers that it was the side effects of chemotherapy". Sadiya.

\subsubsection{Cost of treatment}

This theme highlights the financial burden of breast cancer on the respondents. It is well known that breast cancer has a profound financial implication on its victims. The financial impact of breast cancer comes in two forms which are direct and indirect cost.

\section{Direct cost}

All the respondents revealed that they don't know the exact amount of money spent on the treatment of breast cancer. The reasons they gave were:

(1) They are not the ones that pay for the full treatment. They get financial support from family members, relatives and religious bodies. So they can't tell the exact amount spent.

"I don't know the amount of money spent on the treatment because my brothers are the ones paying for everything". Falmata.

"I don't know the exact estimate of the financial expenses because everything is done by my relatives". Khadija.
(2) Some attributed their reasons for not knowing the exact financial cost to lack of record of all expenditures. All the respondents did not record financial expenses.

"I can't tell how much I spent on this sickness because I don't record the expenses" Shamsiya.

\section{(3) Some attributed it to lack of formal education.}

"My lack of western education makes me not able to record expenditure". Zainab.

Despite the fact that all of them don't know the exact amount of money spent on the treatment and other logistics but they were able to give a fair estimate when further probed. They emphasized that the values given are not the exact amount but a fair estimate of the direct cost of treatment. All of the respondents voiced out concern that the treatment is very costly.

"Everything about breast cancer is very expensive. From the investigations to buying of drugs, everything is just expensive" Rabi lamented.

When further probed, respondents took time and estimated various amounts of money spent treatment ranging from 553 USD to over 2,766 USD. Fauziya who was diagnosed of breast cancer a year ago reported the least amount of money spent the treatment.

"For a rough estimate, I will say that I spent nothing less than 200 thousand naira of which I spent 70 thousand naira on chemotherapy alone" Fauziya.

Another woman who spent about 6 months on hospitalization revealed that:

"I spent more than 500 thousand naira in federal teaching hospital within 6 months, apart from what I spent in state specialist hospital Yola" Aisha.

Furthermore, one woman who have been diagnosed two years ago and hospitalized for 7 months revealed huge expenses.

"I spent more than a million naira on this treatment. I spent about 33 thousand naira in one day just for test (investigation) in federal teaching hospital alone (apart from what is spent at home before hospitalization). I spent, more than a million, (she emphasized) because I have been buying drugs for 18 months now" Hauwa. 
Still on the direct cost, respondents reported selling one or more different types of properties ranging from land, cows and farm produce. One woman sold land to raise money for treatment.

"I sold my land just because of the treatment. I have suffered" (she added) Deborah.

Another woman reported selling of farm produce in order to raise fund for breast cancer treatment.

"I sold farm produce (beans and groundnut) that I intended to store but the financial burden of this diseases make gave me no choice" Ibome.

Some of the respondents reported selling of animals they rear for profit. It should be noted that these women sold these animals without the intention of selling at such time.

"I sold my goat in order to raise money for my treatment" Hajara

"My brothers sold 3 cows to raise money for my treatment. We have spent everything we have" Sadiya.

Apart from selling properties, the financial burden of breast cancer treatment forced some women to borrow money in other to augment what they have financially.

"I am a civil servant but there are times that I borrow money because my salary alone cannot sustain this type of treatment" Konkebe.

\section{Indirect cost}

The indirect cost is the effect of breast cancer on women's occupation. Breast cancer affects respondents' occupation and sources of income. In the sense some cannot continue with their normal business or even to go to work properly.

"I used to farm and take care of my small garden near my house which usually fetch me money, but since the onset of this sickness, I can't do that again" Samira.

"I use to sell African bean cake but I cannot do that anymore because of my disease condition" Ibome.

Another woman who is a civil servant reported that breast cancer affects her job. The sickness hinders her from attending some workshops and other functions or special assignments that could have earned her money. Furthermore, lack of punctuality at place of work is causing financial problems to her as her employers are not happy with her.

Published by Sciedu Press
"I don't go to work properly as before especially when am on chemotherapy" Blessing.

\subsubsection{Emotional disturbances}

This theme highlights the emotional/psychological impact of breast cancer on the women. The emotional disturbance is as a result of the diagnosis of breast cancer. Most women voiced out that they were emotionally down when diagnosed with breast cancer, on the other hand, some women said the revelation of the diagnosis did not affect them emotionally as they believed that it is the will of God, so they prayed and accepted Gods will.

\section{Crying}

Most of the women (14 out of 22) cried when they were first diagnosed with breast cancer and this is a sign of emotional disturbance.

"I felt very bad and emotionally down. I was not happy for a long period of time" said one 30 year old woman (Maryam).

One woman who had one child said:

"I was deeply disturbed. I lost myself into deep thinking. I was very afraid because I have never undergone a treatment like this" Fauziya.

\section{Gods will}

Some of the women ( 8 out of 22) believed that the disease is Gods doing and there is nothing they can do about it rather than to accept it in good faith.

"I was not moved or discouraged when I was diagnosed with the illness. It didn't move me to thinking" Sadiya.

"When I was told I have the diseases, I just prayed, thank God and accepted His will" Blessing.

One woman further added

"there is nothing I can do about Gods judgement, so I just accepted it in good faith" Suwaiba.

\subsubsection{Relationship}

This theme captures the social impact of breast cancer on its victims. It is apparent from the interviews that breast cancer has no impact on the respondents. This is as a result of social setting of the study. 


\section{Relationship with family}

All the respondents revealed that they are very much comfortable to stay among people and that their spouse, relations and family members are also comfortable to stay around them None of the respondents reveal social stigma or irritating people around them because of the breast cancer.

"Nobody was angry or disturbed because of the treatment or my disease condition" Zainab.

"I am comfortable to stay among people" Hajara.

\section{Relationship with spouse}

Respondents reported that relationship with their spouse remain normal because they all believed it is God's will.

"It has not affected my relationship with my husband or family members" Sadiya.

"It didn't affect my relationship with my husband or family members because they have all accepted Gods judgement. They were not worried about my smelling breast wound because they all know it is an illness" Fatima.

\section{DisCUSSION}

On exploration of the various impact of breast cancer on its victims, the findings of this study revealed pain as the major physical impact, expensive cost of treatment as the major financial impact and crying as the major form of expressing emotional impact by breast patients. These are all in agreement to a previous study which revealed that when breast cancer strikes, it affects the whole domain of an individual (physical, emotional/psychological, financial and social domains). ${ }^{[22]}$ The cardinal physical impact revealed in this study was excruciating pain that does not abate completely which is usually caused by the growing tumour and breast wounds and exacerbated by wound dressing. More so, breast changes, alterations in vital signs and skin changes such as alopecia and darkening of the skin which are mostly the effects of chemotherapy are all part of the physical impact. This is in line with various studies conducted on the physical impact of breast cancer on patients. ${ }^{[22,24,25]}$ It should be noted that some of these physical impacts were not due to the breast cancer itself but to the effect of chemotherapy and other drugs, this is in line Monica opinion. ${ }^{[23]}$

The cardinal financial impact of breast cancer revealed by this study is expensive cost of treatment. Although most of the victims don't know the exact amount of money spent on the treatment of breast cancer, but an estimate was possible which revealed that breast cancer patients spend about 560 USD to over 2,766 USD ( keeping in mind that the minimum wage of an average Nigerian worker is 50 US dollars). Notably, this estimated cost of treatment depends on the number of years a patient is diagnosed with breast cancer, as those on treatment for about a year spent nothing less than 560 USD while those who are on treatment for more than 3 years spent nothing less than 2,766 USD. Furthermore, all the women interviewed reported that breast cancer treatment is costly to the point that they had to sell properties and belongings while some borrow money in order to raise money for the treatment. More so, the financial impact of breast cancer is not always a direct one as some victims could not do their normal business while some couldn't do their jobs as before because of the illness as such more financial impact was implicated. Additionally, looking at the fact that most of the women interviewed were housewives, the financial impact becomes more horrendous as the victims usually depend on their spouses, families, relatives and other religious bodies for financial support. All these findings are in line with a study conducted by Fenn. ${ }^{[26]}$ More so, it should be noted that there was no any source of formal support or assistance for this category of patients either from the government or NGOs. More worrisome is the fact that breast cancer is not covered by the national health insurance scheme (NHIS) in Nigeria, therefore even those who are insured with the NHIS cannot benefit from such insurance. This makes the financial impact of breast cancer to be a problem even among working class women.

The findings of this study reveals that the major emotional impact of breast cancer was is crying. Majority of the respondents (18 out of 22) were affected emotionally which was evident in the form of crying, deep thinking, loss of concentration and voicing of feeling bad. This finding is in line to a retrospective study on psychological problems in breast cancer conducted by Malik \& Kiran. ${ }^{[27]}$ Conversely, some of the respondents (4) reported that breast cancer did not affect them emotionally and even those that reported initial emotional disturbances, said it was only for a brief period. The reason for this smooth emotional adaptation is the state of domicile of majority of the respondents which is Gombe state (19 out of 22). The state is dominated by Muslims and Christians. ${ }^{[20]}$ Therefore, women held on to spiritual beings for emotional support while some believe that any type of sickness is ordained by God, therefore, there is no cause to worry.

Perusing at the social impact of breast cancer, several empirical studies revealed that breast cancer has a great social impact on the victims; it affect their relationships, become isolated, marital problems, and make them to avoid people 
or people to avoid them coupled with stigma. ${ }^{[22,28-30]}$ But on the contrary, the findings of this study revealed that breast cancer does not affect their relationship with either spouse or family members. All the respondents revealed that they are comfortable to stay among people (spouse, relatives and family members) and that these people are also comfortable to stay around them. More so, none of the respondents reported any stigma or irritating people around them. The reason for such disparity as revealed by this study is the social setting of respondents. The spouse, family members and relatives perceive that any type of sickness is ordained by God and that anybody can be a victim of such sickness therefore, no need of discrimination against them.

In conclusion, the results of the study revealed that there exists physical impact in the form of pain, financial impact as breast cancer treatment was costly and emotional impact evident in the form of crying, but social impact is not common among respondents in Northern Nigeria. The reason for this deviation from other studies could be because of the people's cultural and religious perception towards the condition. Therefore, the researcher recommends that further studies should be conducted on the influence of religion and culture on the perception of people towards breast cancer patients. Similarly, the Nigerian Health care system should put in place a form of health care financing for patients suffering from long term diseases condition to cushion the huge financial burden of treatment to patients, their family and significant others.

\section{ACKNOWLedgements}

The researchers appreciate Mrs. B. A. Sambo for her support during the process of obtaining ethical clearance for data collection. The researchers similarly, acknowledge the staff of Federal Teaching Hospital, Gombe and State Specialist Hospital for their support and cooperation all through the period of data collection.

\section{REFERENCES}

[1] Kingsley N. BRECAN (Breast Cancer Association of Nigeria: BRSCANs world cancer day event day 2017. Available from: http: //www.brecan.org

[2] Arduino V, Silvia F, Hermann G, et al. Recent cancer survival in Europe: a 2000-02 period analysis of EUROCARE-4 data. Lancet Oncol. 2007; 8: 784-796. https://doi.org/10.1016/S1470-2 045(07) 70246-28

[3] Susan G. Quality of life after breast cancer treatment [blog post]. 2017. Available from: http://www.komen.org/breast-cance r/quality-of-life.html

[4] Mahdi T, Awat F. Awareness levels about breast cancer risk factors, early warning signs, and screening and therapeutic approaches among Iranian adult women: A large population based study using latent class analysis. BioMed Research International. 2014. https://doi.org/10.1155/2014/306352

[5] Omaka - Amari, Ilo, Onwanaka, Umoke. Demographic differences in the knowledge of breast cancer among women in story; state, Nigeria. International Journal of Nursing, Midwives and Health Related Cases. 2015; 1(3): 18-27.

[6] Graham A. Breast cancer epidemiology and risk factors. 2015. Available from: http://emedicine.mescape.com/article169 7353-overview

[7] World Health Organisation [WHO]. Breast cancer: prevention and control. 2013. Available from: https://www . who.int/cancer/d etection/breastcancer/en

[8] Vanderpuyeh V, Grover S, Hammad N, et al. An update on the management of breast cancer in Africa. Infectious Agent and Cancer. 2017; 12: 13.

[9] Stephen P. How will breast cancer change my life? Temporary and permanent changes will transform you. 2017. Available from: https://www.verywell.com/how-will-brest-cance $r$-change-my-life-430677

Published by Sciedu Press
[10] Sonia M, Carla C, Maria C. Pathway for psychological adjustment in breast cancer: A longitudinal study on coping strategies and post traumatic growth. Psychology and Health. 2012; 27(11): 1323-1341.

[11] Macmillan Cancer Support. Long-term consequences of cancer and its treatment. 2013. Available from: https://www .macmillan.org.uk/documents/aboutus /newsroom/consequences_of_treatment_june2013.pdf

[12] Food and Drug Administration [FDA]. Breast cancer: The voice of the patient report. U.S food and drug administration's patient focused drug Development initiative. 2015. Available from: http: //www.fda.gov/drugs/news-events/ucm421313.html

[13] Nwaneri A, Osuala E, Okpala P, et al. Knowledge and awareness of breast cancer among rural women in Umuowa Orlu Local Government Area Imo State, South East, Nigeria. Nigerian Journal of Clinical Practice. 2017 Apr; 20(4): 489-494.

[14] Olajide T, Ugburo A, Habeebu M, et al. Awareness and practice of breast screening and its impact on early detection and presentation among breast cancer patients attending a clinic in Lagos, Nigeria. Nigerian Journal of Clinical Practice. 2014; 17(6): 802-807. PMid:25385923. https://doi.org/10.4103/1119-3077.1444 04

[15] Habu H, Emmanuel C, Inuwa A, et al. Knowledge and Practice of Breast Self-Examination Among Female Nursing Students in University of Maiduguri, Borno State, Nigeria. International Journal of Clinical Oncology and Cancer Research. 2017; 2(3): 57-64. Available from: http://www.sciencepublishinggroup.com/j/ijcocr

[16] Gombe State Government. Gombe state Nigeria. 2016. Available from: http://gombestate.gov.ng/history. 21

[17] City Population. Gombe state in Nigeria. 2017. Available from: https://www.citypopulation.de/php/nigeria-adm in . php?admin1id=NGA016

[18] Trueman C. Structured interviews. 2015. Available from: http://www.historylearningsite.co.uk/sociology/re saerch-methods-in-sociology/structured-interviews/ 
[19] Lawrence L. Validity, reliability, and generalizability in qualitative research. Journal of Family Medicine and Primary Care. 2015 JulSep; 4(3): 324-327. https : //doi .org/10.4103/2249-4863.16 1306

[20] Chepkemoi J. What Languages Are Spoken In Nigeria? 2017. Available from: https://www.worldatlas.com/articles/what-1 anguages-are-spoken-in-nigeria.html

[21] Rucker M. 3 straight forward methods for analysing qualitative interview data. 2016. Available from: http://unstick.me/3-straight-forward-methods-f or-analysing-qualitative-interview-data

[22] Patel G. The psychosocial impact of breast cancer diagnosis and treatment in black and south Asian women. Research Journal. 2013 2: 21-180. Available from: http/:eprints.uwe.ac.uk/20.99/ ressoa-peixoto.

[23] Monica B. Living with breast cancer: understanding the physical and mental changes. 2016. Available from: http:/www. healthl ine.com/health/breast-cancer/how-does-breast-cance $r$-affect-the-body-(hash) side-effects 4

[24] Bouskil K, Kramer M. The impact of cancer and quality of life among long term survivors of breast cancer in Austria. Support Cancer Care.
2016; 24: 4705

[25] Patel G, Harcourt D, Nagvi H, et al. Black and south Asian women experience of breast cancer: A qualitative study. Research Journal. 2014; 136: 147.

[26] Fenn M, Evans S, McCorkle R, et al. Impact of financial burden of cancer on survivors' quality of life. Journal of Oncology Practice. 2014; 10(5): 332-338.

[27] Malik A, Kiran T. Psychological problems in breast cancer patients: A review. Chemotherapy. 2013; 2: 115.

[28] Shrestha K. Psychological impact of mastectomy among Nepalese women: a qualitative study. Nepal Medical Journal. 2012; 14(2): 153-156.

[29] Al-Azri M, Al-Awasi H, A-Rasbi S, et al. Psychosocial impact of breast cancer diagnosis among Omani women. Oman Medical Journal. 2014; 29(6): 437-444.

[30] Faria L. The nurses' role in the psychosocial support for women diagnosed with breast cancer (Bachelor's thesis). Lapland University of applied sciences, Kemi, Finland. 2014. Available from: https://www. thesisus.fi/bitstream/handle/10024 /81825/faria_lucas.pdf?sequence $=1$ 